"A connectedness analysis of German financial institutions during the financial crisis in 2008"

\begin{tabular}{ll} 
AUTHORS & $\begin{array}{l}\text { Carsten Jentsch } \\
\text { Julia Steinmetz }\end{array}$ \\
\hline ARTICLE INFO & $\begin{array}{l}\text { Carsten Jentsch and Julia Steinmetz (2016). A connectedness analysis of } \\
\text { German financial institutions during the financial crisis in 2008. Banks and Bank } \\
\text { Systems, 11(4), 8-19. doi:10.21511/bbs.11(4).2016.01 }\end{array}$ \\
\hline DOI & http://dx.doi.org/10.21511/bbs.11(4).2016.01 \\
\hline RELEASED ON & Friday, 09 December 2016 \\
\hline JOURNAL & "Banks and Bank Systems" \\
\hline FOUNDER & LLC "Consulting Publishing Company "Business Perspectives"
\end{tabular}

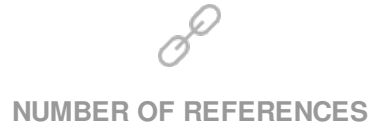

0

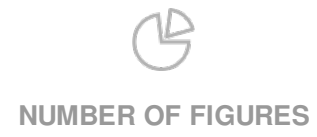

0

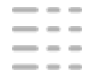

NUMBER OF TABLES

0

(C) The author(s) 2023. This publication is an open access article. 
Carsten Jentsch (Germany), Julia Steinmetz (Germany)

\title{
A connectedness analysis of German financial institutions during the financial crisis in 2008
}

\begin{abstract}
For core financial market activities like risk management and asset pricing, it appears to be crucial to investigate the "connectedness" among financial institutions. In times of economic crises, a suitable measure of connectedness can provide valuable insights of financial markets and helps to understand how institutions influence each other. In particular, depending on contractual obligations between financial institutions, the financial distress at a bank with large systemic impact is likely to cause also distress at other institutions. In the literature, the latter phenomenon is generally tagged by 'contagion' and can eventually result in severe economic crises.

The purpose of this paper is to investigate the connectedness among German financial institutions during the global financial crisis 2007-2009, where the authors focus particularly on 2008 and its height in September 2008 with the bankruptcy of Lehman Brothers. They make use of the definition of connectedness, as it was recently proposed by Diebold and Yilmaz (2014). Their approach relies on analyzing multiple time series of volatilities by a vector autoregressive (VAR) model and a generalized forecast error variance decompositions. It provides several meaningful measures of connectedness and allows for static (average), as well as dynamic (daily time-varying) analyses. The authors show that the connectedness in Germany can be described well by the model.
\end{abstract}

Keywords: connectedness, contagion, generalized variance decomposition, networks, spillover effects. JEL Classification: C32, C58, G32, G33.

\section{Introduction}

One central aspect of modern risk management is to analyze the interdependence of certain actors on the financial market. Measuring these interdependences between financial institutions becomes very important during times of economic crises to judge e.g. contagiousness in a market. In particular, since the global financial crisis during 2007-2009, 'connectedness' between financial institutions has been discussed extensively not only in the US, but also in Europe. The Basel Committee comments on the risk of contagion in a market as follows (Basel Commitee on Banking Supervision, 2011, p. 7):

"Financial distress at one institution can materially raise the likelihood of distress at other institutions given the network of contractual obligations in which these firms operate. A bank's systemic impact is likely to be positively related to its (inter)connectedness visà-vis other financial institutions".

Analyzing the connectedness in financial markets appears to be central to understanding the inner workings of these markets. It is important for core financial market activities like risk management and asset pricing. For example, connectedness is helpful to analyze key aspects of market risk, credit risk, as well as systemic risk and it is also central to understanding macroeconomic (business cycle) risk. Especially in times of crisis, investigating connectedness can provide valuable insights into questions like how institutions influence each other.

(C) Carsten Jentsch, Julia Steinmetz, 2016.

Carsten Jentsch, Dr., Department of Economics, University of Mannheim, Germany.

Julia Steinmetz, Department of Economics, University of Mannheim, Germany.
Unfortunately, there exists no natural definition of financial or economic connectedness or a measure for it. In general, connectedness shall be based on contractual obligations between firms. These can be found in the balance sheets of firms, but a high frequency analysis of balance sheets is usually not feasible. A couple of different approaches to conceptualize and to measure connectedness at various levels have been proposed in the literature. Adrian and Brunnermeier (2011) use Conditional Value at Risk (CoVaR) to consider the situation between individual firms and the overall market. This approach measures systemic risk of a firm as the difference of market Value at Risk and firm distress. On the other hand, Acharya et al. (2010), Brownless and Engle (2012) and Engle et al. (2014) use Marginal Expected Shortfall to measure systemic risk. Hautsch et al. $(2014,2015)$ predict systemic connectedness of a firm as the marginal impact of individual downside risks on systemic distress by using a Value at Risk approach.

In this paper, we use the popular concept of connectedness, as it has been recently proposed by Diebold and Yilmaz $(2012,2014,2015)$. Their approach relies on analyzing multiple time series of volatilities by a vector autoregressive (VAR) model and to measure connectedness in several ways based on forecast error variance decompositions. Their concept allows the definition of several natural and insightful measures of connectedness among financial asset returns and volatilities. Furthermore, these variance decompositions define weighted, directed networks which relate their connectedness measures to those used in network literature. The approach of Diebold and Yilmaz has been used in equity return volatility to analyze connectedness among US financial institutions during 1999- 
2010 in Diebold and Yilmaz (2014), as well among major US and European financial institutions during 2004-2014 in Diebold and Yilmaz (2016). Using policy uncertainty as input data, it has been used by Alter and Beyer (2014), whereas Klößner and Sekkel (2014) consider a modification where the connectedness is defined based on generalized impulse responses instead of variance decompositions.

The contribution of this paper is to measure and analyze the connectedness among financial firms in Germany at various levels based on the approach of Diebold und Yilmaz (2014). Based on raw highfrequency stock price data for 2008 , we construct a multiple time series of volatilities for German financial firms listed on the stock exchange and traded on active liquid markets. The data were provided by the Karlsruhe Institute of Technology (KIT). The data set includes all trades on each trading day for each stock on the electronic trading platform XETRA ${ }^{1}$. In particular, we focus on September 2008, the height of the financial crisis from 2007 to 2009, where Lehman Brothers went bankrupt. To analyze the data, we consider both average and daily timevarying connectedness measures.

The paper is organized as follows. Section 1 introduces the concept and describes the methodology of connectedness. In section 2 , the results of the connectedness analysis of German financial firms are shown and discussed in detail. The final section concludes.

\section{The methodology of connectedness}

1.1. VAR modeling of volatilities. The concept of connectedness, as introduced by Diebold and Yilmaz (2014), is based on stable vector autoregressions of order $p$ to model time series of daily realized volatilities $\mathbf{Y}_{\mathbf{t}}$, i.e.

$Y_{t}=\sum_{i=1}^{p} A_{i} Y_{t-i}+u_{i}$

where $Y_{t}=\left(Y_{1 t}, \ldots, Y_{N t}\right)^{T}$ denotes the $(N \times 1)$ vector of volatilities of $N$ considered firms at time $t$, $A_{i}, i=1, \ldots, p$ are $(N \times N)$ autoregressive coefficient matrices and $u_{t} \sim\left(0, \Sigma_{u}\right)$ is a white noise process with mean zero $E\left[u_{t}\right]=0$ and positive definite covariance matrix $E\left[u_{t} u_{t}^{T}\right]=\Sigma_{u}$. Note that (1) has also a vector moving average (VMA) representation

$Y_{t}=\sum_{i=1}^{\infty} \Phi_{i} u_{t-i}$,

where $\Phi_{i}, i=0,1,2, \ldots$ are $(N \times N)$ moving average coefficient matrices and $\Phi_{0}=I_{N}$ is the $(N \times N)$ identity matrix. Hence, $\hat{Y}_{t+H}=\sum_{i=1}^{H} \Phi_{i} u_{t+H-i}$ is the forecast (at horizon $H$ ) of $Y_{t+H}$, which leads to a forecast error term

\footnotetext{
${ }^{1}$ An all-electronic trading system based in Frankfurt, Germany, which accounts for more than $90 \%$ of all stock trades on the Frankfurt Exchange.
}

$Y_{t+H}-\widehat{Y}_{t+H}=\sum_{h=0}^{H-1} \Phi_{h} u_{t+H-h}$

with corresponding forecast error variance matrix

$\Sigma_{Y}^{H}=\sum_{h=0}^{H-1} \Phi_{h} \Sigma_{u} \Phi_{h}^{T}$.

Note that $\Sigma_{Y}^{H}$ is equal to the optimal mean squared error (MSE) predictor. As the $\Phi_{i}$ 's and $\Sigma_{u}$ will be unknown in general, they have to be estimated from data. Having observations $Y_{1}, \ldots, Y_{T}$ at hand, this can be done by using, e.g., least-squares estimation of the VAR coefficient matrices to get $\widehat{A}_{l}, i=1, \ldots, p$ and $\widehat{\Sigma}_{\text {u }}$, by computing the sample variance matrix of the VAR residuals $\widehat{u_{t}}=\sum_{i=1}^{p} \hat{A}_{i} Y_{t-i}, t=p+1, \ldots, T$. As the $\Phi$ 's are recursively defined by $\Phi_{s}=\sum_{j=1}^{s} A_{j} \Phi_{s-j}$ with $s=1,2, \ldots$, where $\mathrm{A}_{j}=0$ for $j>p$, we get estimators $\widehat{\Phi}_{i}$ similarly by using $\widehat{\mathrm{A}}_{i}, i=1, \ldots, p$. However, in particular over long time horizons or during crises, the $\Phi_{i}$ 's will usually not be constant over time, that is, the data generating process (DGP) will not be time-stationary. Hence, it is reasonable to estimate time-varying parameters $\Phi_{i}(\mathrm{t})$. For this purpose, we consider a uniform one-sided estimation window with width $\omega$, where for each time point, only the most recent $\omega$ time points enter the estimation with equal uniform weights.

The VMA coefficients contain all contemporaneous and dynamic features of the multivariate time series system. Instead of analyzing these coefficients directly, an alternative way is to use variance decompositions (see, e.g., Lütkepohl, 2007). The variance decomposition indicates the amount of information each variable contributes to the other variables. It determines how much of the $H$-step-ahead forecast error variance of each of the variables in forecasting $Y_{i t}$ can be explained by shocks. Note that the VAR innovations $u_{t}$ are generally contemporaneously correlated, but the calculation of variance decompositions does require orthogonal innovations. One common solution to transform the model to get orthogonal innovations is to use the Cholesky factorization. Instead of using this Cholesky approach that depends on the orderings of the variables, Diebold und Yilmaz (2014) propose to use the generalized variance decomposition by Koop et al. (1996) and Pesaran und Shin (1998). This generalized approach uses correlated shocks instead of orthogonal shocks, but factors into the calculation of the distribution of the historically observed errors.

1.2. Generalized variance decomposition. In comparison to the special case of orthogonal shocks $\left(\mathrm{u}_{\mathrm{t}}\right)$ in (1) that allows an application of a standard variance decomposition, this is not possible if the shocks are correlated. As discussed in Diebold and Yilmaz (2014, p. 5), reduced-form shocks are rarely orthogonal and it is inevitably necessary to make 
assumptions to identify uncorrelated structural shocks from correlated reduced-form shocks. To address this issue, they suggest to use the generalized variance decomposition (GVD) introduced by Koop et al. (1996) and Pesaran und Shin (1998) instead of using Cholesky factorization. If the latter approach is used, the analysis will unintentionally depend on the ordering of the variables in the VAR system. Nevertheless, the GVD requires normality of the shock distribution, which is the price to pay here. For reaching normality, we shall let our connectedness analysis be based on return volatilities instead of returns, since volatilities tend to be much more serially correlated than returns (compare Diebold und Yilmaz, 2014, p. 14). Further, to make the data more normal-like, we take logarithms.

In general, for variance decompositions, own variance shares are defined to be the fractions of the $H$-step-ahead error variances in forecasting $Y_{i t}$ due to shocks to $i$, for $i=1, \ldots, N$ and spillovers to be the fractions of the $H$-step-ahead error in forecasting $Y_{i t}$ due to shocks to $j$, for $i, j=1,2, \ldots, N$, such that $i \neq j$. The $H$-step-ahead generalized variance decomposition matrix $D^{g H}=\left[d_{i j}^{g H}\right], i, j=1, \ldots, N$ is defined to have entries

$d_{i j}^{g H}=\frac{\sigma_{j j} \sum_{h=0}^{H-1}\left(e_{i}^{T} \Phi_{h} \Sigma_{u} e_{j}\right)^{2}}{\sum_{h=0}^{H-1}\left(e_{i}^{T} \Phi_{h} \Sigma_{u} \Phi_{h}^{T} e_{i}\right)} \cdot 100$,

where $e_{j}$ is a selection vector with $j$-th element unity and zeros elsewhere, $\Phi_{h}$ is the $h$-th moving-average coefficient matrix, $\Sigma_{u}$ is the covariance matrix of the error terms and $\sigma_{j j}$ is the $j$-th diagonal element of $\Sigma_{u}$.

Note that the denominator is the forecast error variance of variable $i$ and the numerator is the contribution of shocks in variable $j$ to the $H$-stepahead forecast error variance of variable $i$. As shocks need not to be orthogonal, forecast error variation contributions do not necessarily sum up to 100 , i.e., row sums of $D^{g H}$ are not necessarily equal to 100 . Hence, to be able to interpret the entries of a variance decomposition matrix as shares, they have to be scaled. That is, we shall use $\widetilde{D}^{g H}=\left[\tilde{d}_{i j}^{g H}\right]$ with $\tilde{d}_{i j}^{g H}=\frac{d_{i j}^{g H}}{\sum_{j=1}^{N} d_{i j}^{g H}}$ instead of $D^{g H}$ in the following.

Table 1. Connectedness table

\begin{tabular}{lccccc}
\hline & $x_{1}$ & $x_{2}$ & $\ldots$ & $x_{N}$ & From Others \\
\hline$x_{1}$ & $\tilde{d}_{11}^{g H}$ & $\tilde{d}_{12}^{g H}$ & $\ldots$ & $\tilde{d}_{1 N}^{g H}$ & $\sum_{j=1, j \neq 1}^{N} \tilde{d}_{1 j}^{g H}$ \\
$x_{2}$ & $\tilde{d}_{21}^{g H}$ & $\tilde{d}_{22}^{g H}$ & $\ldots$ & $\tilde{d}_{2 N}^{g H}$ & $\sum_{j=1, j \neq 2}^{N} \tilde{d}_{2 j}^{g H}$ \\
$\vdots$ & $\vdots$ & $\vdots$ & $\ddots$ & $\vdots$ & $\vdots$ \\
$x_{N}$ & $\tilde{d}_{N 1}^{g H}$ & $\tilde{d}_{N 2}^{g H}$ & $\ldots$ & $\tilde{d}_{N N}^{g H}$ & $\sum_{j=1, j \neq N}^{N} \tilde{d}_{N j}^{g H}$ \\
\hline \multirow{2}{*}{ To Others } & $\sum_{i=1, i \neq 1}^{N} \tilde{d}_{i 1}^{g H}$ & $\sum_{i=1, i \neq 2}^{N} \tilde{d}_{i 2}^{g H}$ & $\ldots$ & $\sum_{i=1, i \neq N}^{N} \tilde{d}_{i N}^{g H}$ & $\frac{1}{N} \sum_{i, j=1, i \neq j}^{N} \tilde{d}_{i j}^{g H}$ \\
\hline
\end{tabular}

1.3. The connectedness table. The entries of $\widetilde{D}^{g H}$ can be used to analyze the connectedness between assets $i$ and $j$. More precisely, as described in Diebold und Yilmaz (2014), the matrix $\widetilde{D}^{g H}$ leads to a so-called Connectedness table, which displays pairwise, as well as system-wide connectedness (see Table 1). The connectedness table is central for understanding the different types of connectedness and their relation that will be defined below.

For a system with $N$ variables $\left(Y_{1 t}, \ldots, Y_{N t}\right)$, its upper-left $(N \times N)$-block matrix contains the scaled generalized variance decomposition matrix of the $\mathrm{H}$ step-ahead forecast error, i.e. $\widetilde{D}^{g H}$. Its rightmost column contains row sums, the bottom row contains column sums, and the lower-right element contains the average of the column sums (equal to the average of the row sums), where, in all cases, $i \neq j$, i.e. the diagonal elements are excluded. The off- diagonal entries of $\widetilde{D}^{g H}$ measure pairwise directional connectedness from $j$ to $i$ and, following the notation in Diebold und Yilmaz (2014), we set

$\tilde{C}_{i \leftarrow j}^{g H}=\tilde{d}_{i j}^{g H}$.

Note that $\tilde{C}_{i \leftarrow j}^{g H} \neq \tilde{C}_{j \leftarrow i}^{g H}$ in general. The net pairwise directional connectedness from $j$ to $i$ is defined as

$\tilde{C}_{i j}^{g H}=\tilde{C}_{j \leftarrow i}^{g H}-\tilde{C}_{i \leftarrow j}^{g H}$.

The off-diagonal row and column sums, labeled "From Others" and "To Others" in the connectedness table, define total directional connectedness from others to $i$ ("from" connectedness) as

$\tilde{C}_{i \leftarrow \circ}^{g H}=\sum_{j=1, i \neq j}^{N} \tilde{d}_{i j}^{g H}$

and the total directional connectedness to others from $j$ ("to" connectedness) is defined as 
$\tilde{C}_{\circ \leftarrow j}^{g H}=\sum_{i=1, i \neq j}^{N} \tilde{d}_{i j}^{g H}$.

Analogously, the net total pairwise directional connectedness ("net" connectedness) is defined as

$\tilde{C}_{i}^{g H}=\tilde{C}_{\circ \leftarrow i}^{g H}-\tilde{C}_{i \leftarrow \circ}^{g H}$.

Finally, the grand total of the off-diagonal-entries in $\widetilde{D}^{g H}$ divided by $N$ (equivalently, the average of the "From Others" column or "To Others" row) measures total connectedness

$$
\tilde{C}^{g H}=\frac{1}{N} \sum_{i, j=1,}^{N} \tilde{d}_{i j}^{g H} .
$$

\section{Connectedness analysis of German financial institutions}

In this section, we make use of the connectedness tools described in Section 1 to monitor and characterize the evolution of connectedness among German financial institutions during 2008. We proceed in four steps. First, in section 2.1, we describe the data set that we use as the basis for our connectedness analysis. Next, we conduct a static and a dynamic connectedness analysis in sections 2.2 and 2.3, respectively. In section 2.4, we take a closer look at the impact of Lehman Brothers' bankruptcy. Finally, in section 2.5, we comment on the robustness of our results with respect to the choice of model parameters.

Table 2. Overview of financial institutions (deadline for the capital data was December 31)

\begin{tabular}{|l|c|c|c|c|c|}
\hline \multirow{2}{*}{ Institution } & \multirow{2}{*}{ Label } & \multirow{2}{*}{ Business } & \multicolumn{3}{c|}{ Market capital in billion $€$} \\
\cline { 4 - 6 } & & 2007 & 2008 & 2009 \\
\hline Deutsche Bank AG & Dtb & Universal bank & 47.42 & 15.89 & 30.68 \\
\hline Commerzbank AG & Com & Universal bank & 1.73 & 0.48 & 0.70 \\
\hline $\begin{array}{l}\text { Deutsche Postbank } \\
\text { AG }\end{array}$ & Pos & $\begin{array}{c}\text { Commercial } \\
\text { bank }\end{array}$ & 9.96 & 3.39 & 5.00 \\
\hline Comdirect bank AG & CoD & Direct bank & 1.18 & 0.87 & 0.93 \\
\hline $\begin{array}{l}\text { IKB Dt. Industrie- } \\
\text { bank AG }\end{array}$ & IKB & Credit intuition & 0.54 & 0.10 & 0.43 \\
\hline Aareal Bank AG & AAr & $\begin{array}{c}\text { Real estate } \\
\text { bank }\end{array}$ & 1.34 & 0.25 & 0.57 \\
\hline Allianz SE & All & Insurance & 66.60 & 33.98 & 39.56 \\
\hline MünchnerRück AG & Mue & Insurance & 28.97 & 22.91 & 21.45 \\
\hline
\end{tabular}

2.1. The data set. The basis for our connectedness analysis is a high-frequency intra-day data set for 2008 from XETRA provided by KIT that contains stock prices $p$ of German financial institutions for all trades during trading hours from 09:00-17:30. We filtered the available prices in 5 -minute intervals ${ }^{1}$, which results in 104 intra-day prices at times 9:00, 9:05, 9:10, ..., 17:30 for all 253 trading days in 2008. Precisely, we examine eight German financial institutions. Table 2 provides an overview of the considered firms during the crisis of 2007-2009. The sample includes two universal banks,

${ }^{1}$ If no price was available at that time, we used the most recent one. one commercial bank, one direct bank, one credit bank, one real estate bank and two insurance companies. This choice of firms may seem arbitrary, but a lot of banks in Germany are primary savings banks (Sparkassen), Landesbanken or cooperative banks ${ }^{2}$. Thus, only a few banks are corporations that are suitable for a connectedness analysis based on volatilities. Moreover, our choice covers only stocks that are traded frequently enough. For all firms, the daily realized return volatility is calculated based on the high-frequency intra-day data, as the sum of squared log price changes over the 104 5-minute intervals during trading hours. This gives

$Y_{i t}=\sum_{i=2}^{104}\left(\log p_{i, t}-\log p_{i-1, t}\right)^{2}$,

where $p_{i t}$ describes the stock price at interval $i=$ $1, \ldots, 104$ and trading day $t=1, \ldots, 253$. Figure 1 shows the daily realized volatility for each considered firm. Instead of balance sheet information, we use return volatilities, which depend (thus, not only) on the forward-thinking assessment of brokers. Hence, we consider volatility connectedness, as suggested by Diebold und Yilmaz (2014), because volatility tracks investors' fear (e.g., "VDAX" or "VDAX New") and it is crisis sensitive, whereas crises will be of much interest to us.

2.2. Static connectedness analysis. Based on the volatility data pre-processed, as described in section 2.1 above, a static connectedness analysis is conducted. The analysis is static in the sense that we set $\omega \rightarrow \infty$ in our analysis in this section leading to an "in average" connectedness analysis. Furthermore, we use a VAR(3) approximating model and a forecast horizon of $H=12$. The latter choice was used also in Diebold und Yilmaz (2014) and was motivated, e.g., by the 10day Value at Risk (VaR) required under the Basel accord. In section 2.5, we discuss the robustness to the choice of VAR order and forecast horizon.

Table 3 shows the connectedness among the considered institutions. For each firm, the diagonal entries of the upper-left matrix ("own connectedness") are the largest ones in each column, especially for IKB and comdirect bank. However, in most of the cases, the total directional connectedness ("From Others" or "To Others") is larger than the "own connectedness". The total connectedness, the mean of the total directional connectedness ("from" and "to" are equal by definition), is of medium size 46.51. The total connectedness describes the average impact of connectedness.

First, we look at the pairwise directional connectedness $\tilde{C}_{i \leftarrow j}^{g H 4}$ for all $i, j=1, \ldots, 8$ and $i \neq j$. We observe the largest value of pairwise directional

${ }^{2}$ see Detzer et al. (2014) for a short overview about the German banking system.

${ }^{3}$ see, e.g., boerse.de (2016).

${ }^{4}$ We suppress the exponent $g H$ for better readability throughout this section. 
connectedness from Allianz to Münchner Rück

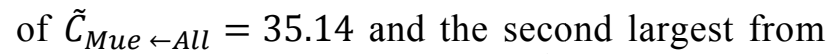
Münchner Rück to Allianz of $\tilde{C}_{A l l} \leftarrow M u e=19.58$. These two companies are the two largest insurance companies in Germany and are, along with Deutsche Bank, the largest in our sample in terms of their market capitalization (cf. Table 2).

The large connectedness is reasonable, since
Allianz is still a shareholder of Münchner Rück (Allianz Investor Relations, 2008b) and both are located in the insurance sector.

Hence, it is absolutely plausible that the pairwise connectedness between Allianz and Münchner Rück is large. The net directional connectedness from Münchner Rück to Allianz is $\tilde{C}_{M u e, A l l}=-15.5$.
Volatility of Deutsche Bank

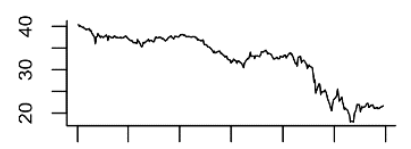

Jan Mrz Mai Jul Sep Nov Jan

Volatility of comdirect bank

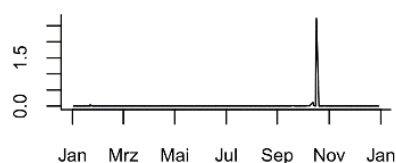

Volatility of Commerzbank

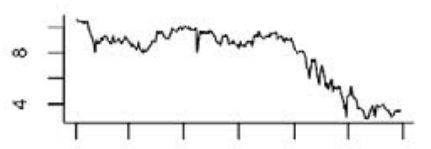

Jan Mrz Mai Jul Sep Nov Jan

Volatility of IKB

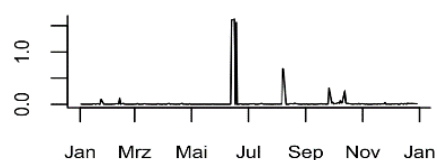

Volatility of Postbank

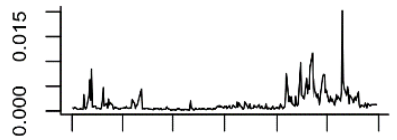

Jan Mrz Mai Jul Sep Nov Jan

Volatility of Aareal Bank

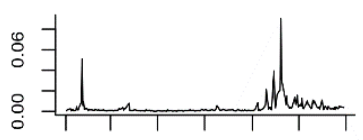

Jan Mrz Mai Jul Sep Nov Jan

Volatility of Allianz

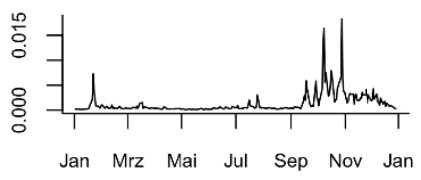

Volatility of Münchner Rück

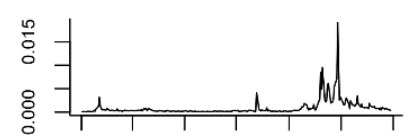

Jan Mrz Mai Jul Sep Nov Jan

Fig. 1. Daily realized volatility during 2008

Table 3. Static connectedness table 2008

\begin{tabular}{|l|c|c|c|c|c|c|c|c|c|}
\hline & Dtb & Com & Pos & CoD & IKB & Aar & All & Mue & From Others \\
\hline Dtb & 54.44 & 3.05 & 9.24 & 0.14 & 0.11 & 14.63 & 11.63 & 6.75 & 45.56 \\
\hline Com & 12.52 & 39.55 & 14.26 & 1.27 & 0.35 & 12.72 & 12.71 & 6.62 & 60.45 \\
\hline Pos & 6.37 & 5.92 & 42.51 & 0.71 & 0.06 & 16.56 & 19.25 & 8.61 & 57.49 \\
\hline CoD & 4.02 & 8.44 & 2.84 & 77.66 & 0.13 & 1.80 & 2.55 & 2.56 & 22.34 \\
\hline IKB & 0.68 & 0.52 & 0.19 & 0.02 & 98.01 & 0.24 & 0.22 & 0.11 & 1.99 \\
\hline Aar & 6.05 & 7.51 & 11.55 & 0.87 & 0.10 & 42.96 & 26.60 & 4.35 & 57.04 \\
\hline All & 8.00 & 4.71 & 13.64 & 0.79 & 0.02 & 14.93 & 38.35 & 19.56 & 61.65 \\
\hline Mue & 9.18 & 2.13 & 10.40 & 0.70 & 0.02 & 7.97 & 35.14 & 34.45 & 65.55 \\
\hline To Others & 46.83 & 32.29 & 62.13 & 4.50 & 0.78 & 68.87 & 108.11 & 48.56 & 46.51 \\
\hline Net total & 1.27 & -28.16 & 4.64 & -17.84 & -1.21 & 11.83 & 46.46 & -16.99 & 0.00 \\
\hline
\end{tabular}

The impact $\tilde{C}_{C o m} \leftarrow$ All $=12.71$ is also quite pronounced. Allianz officially sold Dresdner Bank to Commerzbank during 2008 for almost 10 billion $€$. But Allianz also became the largest shareholder of Commerzbank with, at first, $18 \%$ and, later, $30 \%$ of the shares (Allianz Investor Relations, 2008a). Hence, the great impact of Allianz to other banks, and particularly to Commerzbank, was expected. Further, the pairwise connection between Aareal Bank and Postbank is also rather large with $\tilde{C}_{A A r \leftarrow P o s}=11.55, \tilde{C}_{P o s} \leftarrow A A r=16.56$ and $\tilde{C}_{P o s, A A r}=-5.01$. In the first two quarters of 2008, Aareal Bank sold a portfolio of private construction financing in amount of 1.5 billion $€$ to Postbank (see Kunisch, 2008).
Deutsche Bank became the largest shareholder of Postbank in 2008. Hence, it is not surprising that the impact of Postbank to other banks is rather large with $\tilde{C}_{D t b \leftarrow P o s}=9.24, \tilde{C}_{\text {Com } \leftarrow P o s}=14.26, \quad \tilde{C}_{A l l \leftarrow P o s}=$ $13.64, \tilde{C}_{\text {Mue } \leftarrow \text { Pos }}=10.40$. Nevertheless, the small role of Deutsche Bank is somewhat surprising, since Deutsche Bank is the largest bank in Germany and located in over 70 countries. In particular, because Deutsche Bank was also affected by the financial crisis. The stock prices of Deutsche Bank decreased during 2008 to less than $15 \%$ of the pre-crisis value (from $105 €$ to $15 €$ ). Note also that Deutsche Bank has to pay a large risk surcharge, because its going bankrupt would have significant effects on the market $^{1}$. Hence, we would have expected the impact of Deutsche Bank on other institutions to be much more pronounced than what we observed in our analysis.

As Commerzbank held 2008 almost $80 \%$ of the shares of comdirect bank, it was also somewhat unexpected that the connection between Commerzbank and comdirect bank turned out to be not noticeable high. But taking a closer look at the Commerzbank column in Table 3 reveals that the impact of a shock occurring in Commerzbank to others, comdirect bank is ranked second with $\tilde{C}_{C o D \leftarrow C o m}=8.44$ after

\footnotetext{
${ }^{1}$ Compare Financial Stability Board (FSB) (2016).
} 
the "own" connectedness. The same is true for a shock occurring in comdirect bank with $\tilde{C}_{C o m \leftarrow C o D}=1.27$, after the "own" connectedness.

The "from" connectedness measures range from 1.99 to 65.55 . It is equal to 100 minus the "own connectedness" taking values between 34.45 and 98.01. In comparison, the "to" connectedness is between 0.78 and 108.11. Note that the sum of impacts to others is not constrained to equal 100 such that "to" connectedness can exceed 100. If the net total directional connectedness is negative, the firm is called a net-receiver and if it is positive, the firm is a net-transmitter. The bottom line in Table 3 shows that Allianz (46.46) and Aareal Bank (11.38) are transmitters, whereas Commerzbank (-28.16), comdirect (-17.84) and Münchner Rück (16.99) are receivers. Deutsche Bank, Postbank and IKB have a net total near to zero and, essentially, turn out to be neither transmitter nor receiver.

2.3. Dynamic connectedness analysis. In comparison to the static connectedness analysis of section 2.2, now we make use of a $\operatorname{VAR}(3)$ approximating model together with a uniform one-sided rolling estimation window of width $\omega=100$ days to estimate time-varying model parameters. For the dynamic connectedness analysis, we proceed in three steps. First, we look at total connectedness, before we turn to total directional connectedness as well as pairwise directional connectedness.

2.3.1. Total connectedness. In Figure 2, the dynamic total connectedness during 2008 is shown. Note that the total connectedness curve is not available till end of May, as we only have data at hand ranging from January 1 to December 31, 2008 and we make use of an estimation window width of 100 days.

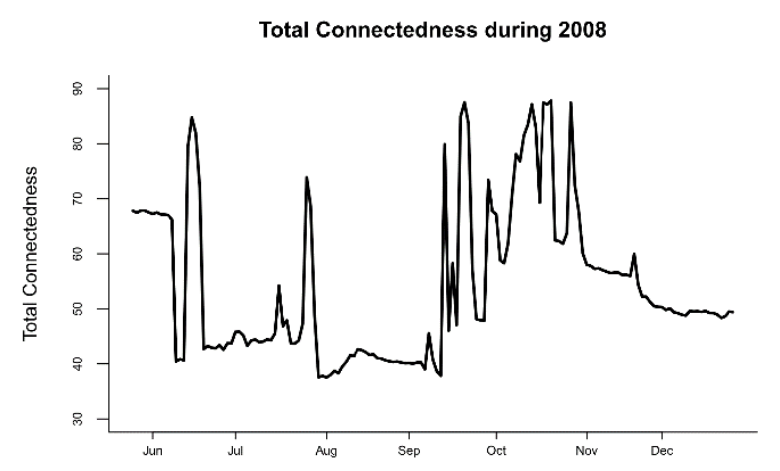

Fig. 2. Dynamic total connectedness during 2008

We observe a strong variation of the total connectedness from 37.53 to 87.82 . In particular, we can see that there exists periods, where the total connectedness is constant till a shock occurs and, then, the total connectedness abruptly goes up. In the middle of September, total connectedness increases and, then, it jumps till the beginning of November. From that point, total connectedness falls constantly till the end of the year. The high variation during September and
October is an indicator that several events occur in the market that heavily influence the stock prices. In the middle of September, the financial crises reached its height in the US and Europe with several bankruptcies. In October, some German banks got into trouble and the Federal Government of Germany passed a rescue package for crisis-affected banks. From the beginning of November, the total connectedness decreases. Several banks needed governmental support of guarantees and money. Hence, the total connectedness drops, because the banks desired to be as independent of the others as possible.

For an explanation of both peaks in June and July, we refer to section 2.3.3. In section 2.4, we have a closer look at September 2008 to explain the large variation of connectedness observed during this period.

2.3.2 Total directional connectedness. In Figure 3, time series of total directional connectedness ("to", "from" and "net") are plotted for each financial institution. We observe that for all firms, the "to" connectedness (systematically) varies much more over time than the "from" connectedness. The latter phenomenon is explained by Diebold und Yilmaz (2014) by the fact that, in particular, large shocks are expected to be transmitted to other stocks. If the stock of a larger (central) institution is shocked, this shock is expected to cause also larger spillover effects. Also, since shocks are quite distinctive in their size and severity and as the transmitted institutions are different, the "to" connectedness has a wider range than "from" connectedness.

As already observed for the total connectedness in Figure 2, we see that the variation of directional connectedness does increase considerably as well for most firms in September and October. This can be explained by idiosyncratic shocks that hit individual stocks during this time period and these shocks had been transmitted to other stocks.

Figure 4 shows the degree distribution for "to" and "from" directional connectedness of all eight firms in terms of their mean, maximum, minimum, 25\%- and $75 \%$ quantiles, respectively. Although, by definition, the means of "from" and "to" connectedness are equal, their distributions turn out to behave very differently. As discussed already above, the variation of "from" connectedness is much lower than the variation of "to" connectedness and the range of the distribution of "from" connectedness is very small in contrast to the range of the "to" connectedness. Moreover, we observe that "from" connectedness is more left-skewed, whereas "to" connectedness gets more right-skewed during the crisis. A comparison of Figure 2 and the left panel in Figure 3 leads to the conclusion that the large total connectedness during September and October 2008 is mainly caused by the large maximum values of the "to" connectedness. That is a signal that a shock occurs in one firm that influences the others to some large extent. 

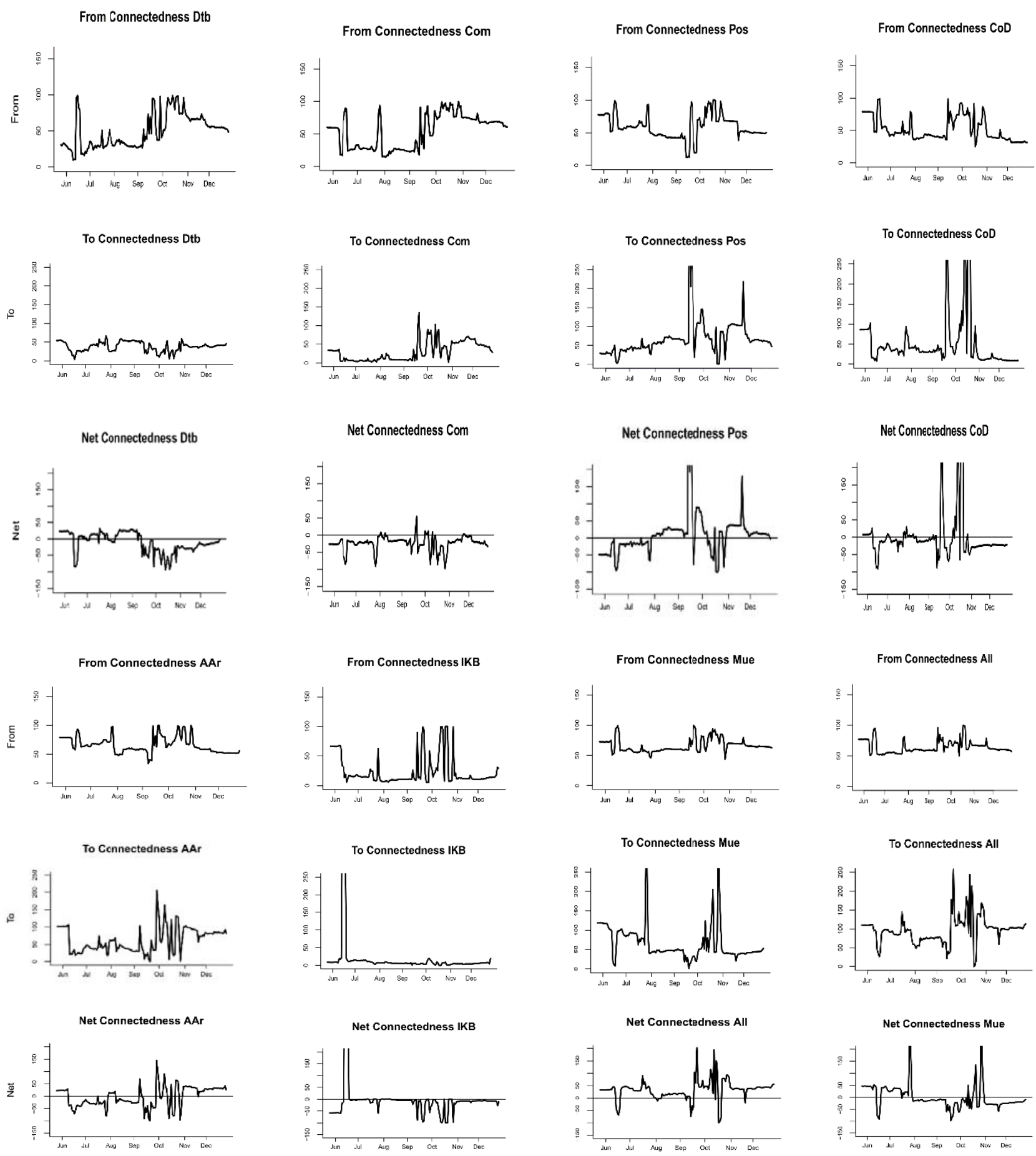

Fig. 3. "To", "from" and "net" directional connectedness during $2008 \omega=100$ and the forecast horizon $H=12$

2.3.3. Pairwise directional connectedness. To see how a shock at one financial institution affects the others, their pairwise connectedness has to be considered, as it does not average or sum up connectedness. In particular, the analysis of dynamic pairwise connectedness is very important to understand the evolution of interdependences among financial firms, for example, during economic crises. This is possible, as we allow the VAR parameters to depend on time by using rolling window estimation, such that the weights of pairwise connectedness between two firms vary also over time.
Given the eight institutions under consideration, it is an infeasible task to present a detailed analysis in the confines of this paper. Hence, we have a short look at the connectedness around June 10 and July 25, respectively (compare also Figure 2). In section 2.4, we will also have a closer look at net pairwise connectedness during the most important days of the crisis in September 2008 around the bankruptcy of Lehman Brothers.

Figure 5 shows networks of "net" pairwise directional connectedness on June 10 and on June 13, where the color of the edges indicates the height of "net" connectedness. 

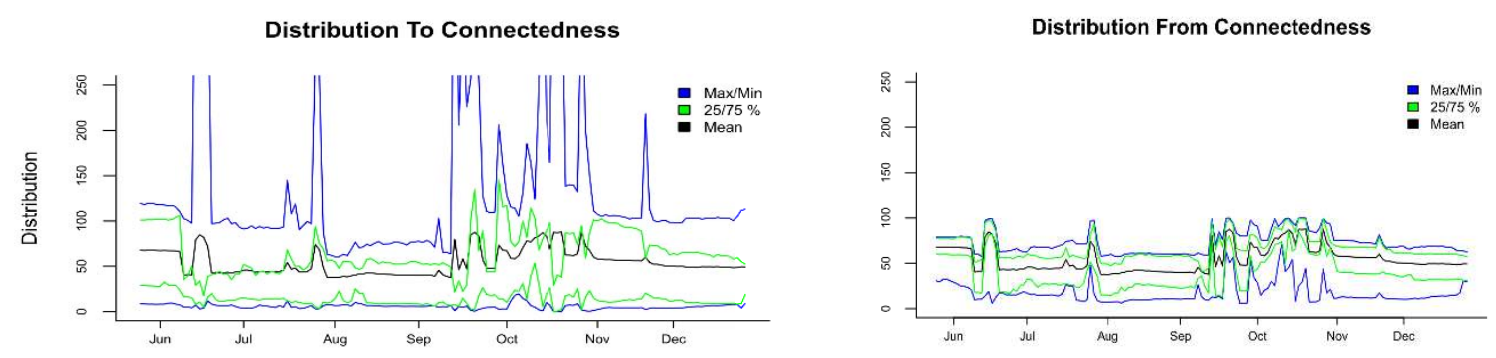

Fig. 4. Distribution of "to" and "from" connectedness during 2008 with the rolling window $\omega=100$ and the forecast horizon $H=12$

We draw only edges corresponding to a "net" connectedness larger than 5 , where black indicates connectedness between 5 and 10, blue between 10 and 20 and red larger than 20. Orange nodes are used for banks, and green nodes for insurances. The node size is an indicator for the market capitalization. We observe that the eight firms are pretty much connected to each other on June 10 with net-transmitters Allianz and Münchner Rück having significant impact on the other institu- tions. For the following day, the connectedness hardly changes. On June 12, the threat exists that the shareholders of IKB will lose their money. With a time shift of one day, we see that IKB becomes a strong nettransmitter on June 13. The shock in IKB affects almost all other firms in the system. For the next days, the "to" connectedness of IKB is very high till June 19. Compare also Figure 2, where the total connectedness shows pronounced jumps around June 10.

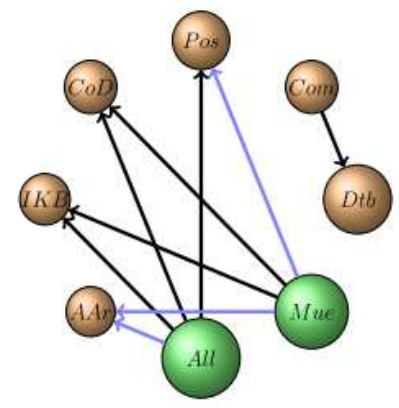

June 10 , total connectedness 40.44

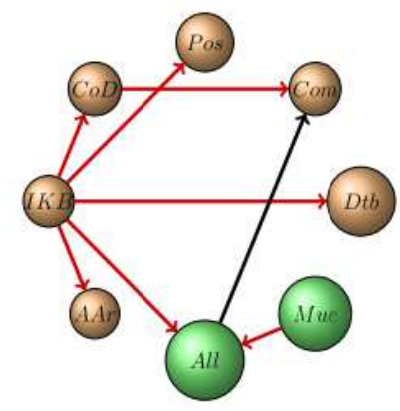

June 13 , total connectedness 79.44

Fig. 5. We plotted all "net" pairwise directional connectedness more than 5 . The black edges describe connectedness between 5 and 10, the blue edges between 10 and 20 and the red ones more than 20. The vertices of Allianz and Münchner Rück are marked green, as they are insurance companies. The node size is an indicator for the stock market capitalization

Similarly, for the end of July, we see in Figure 2 that the total connectedness increased for some days before it fell down again. On July 25, Münchner Rück and another insurance company Hannover Rück announced their expectations about their profit. Since then, it was obvious that the insurance sector in Germany was also affected by the financial crisis. In Figure 6, where "net" pairwise directional connectedness on July 24 and July 25 is shown, we can see a huge increase of "to" connectedness of Münchner Rück after that announcement. In fact, "to" connectedness increased to more than 200. Noticeable is the pairwise connectedness between Münchner Rück and all others, except Deutsche Bank. Since Allianz is also an insurance company, it is not surprising that the impact of Allianz to others increases too.
2.4. Bankruptcy of Lehman Brothers: a detailed connectedness analysis. In this section, we zoom in September 2008 and consider the development of pairwise and net pairwise directional connectedness around the bankruptcy of Lehman Brothers. This daily analysis provides valuable insights to better understand the current stages of the financial crisis and to identify impacts (and roots) of shocks. Table 4 gives an overview of most important events that affected significantly the financial market during September 2008. Figure 7 shows net pairwise directional connectedness for several days. Here, edges are only plotted between pairs of firms if the corresponding net pairwise directional is larger than 5 (note the difference here to Figures 5 and 6). We observe that the strength of connectedness among the firms varies considerably during September. For instance, the total connectedness fluctuates between 37.84 and 87.52 . 


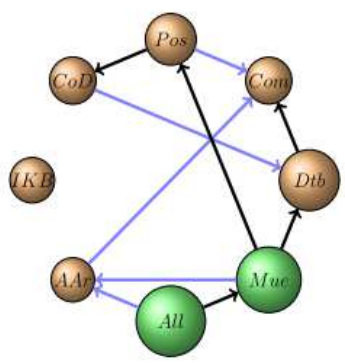

July 24 , total connectedness 47.33

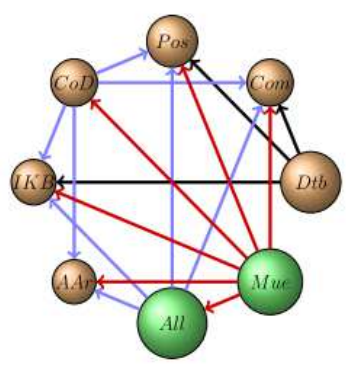

July 25 , total connectedness 73.91

Fig. 6. For description, see figure 5

We begin with the connectedness analysis on September 11. As the liquidity crisis started on September 9, the banks did not trust each other anymore and were not willing to lend money to other banks. The EURIBOR ${ }^{1}$ increased for September and October. The total connectedness on September 11 reaches its second lowest value for the whole year and the "own" connectedness is rather large. Only a few net pairwise connections between the firms are present. The firms want to leave the system and to be independent from the other firms.

On September 12, Deutsche Bank became the greatest single shareholder of Postbank. The total connectedness went up. Noticeable is the substantially increased impact of Postbank on the other firms. More precisely, the from directional connectedness of Postbank is very high with $\tilde{C}_{\circ \leftarrow \text { Pos }}=$ 522.93 and the net pairwise connectedness from Postbank to the single institutions ranges between 47.45 and 86.02. The large connectedness from Postbank to the others remains till September 17. September 15 is also called "Black Monday". Lehman Brothers was bankrupt. The total connectedness falls. The pairwise connectedness between the firms decreases too, except the impact of Postbank to the others. The stock prices of the firms lose about $22 \%$ to $33 \%$ of their value in the following days.

On September 18, Central Banks of America, Europe and Japan offer more than 180 billion USDollar to reduce tensions on the financial market. Banks can lend up to 40 billion Euro for one day, as well as Euro quick tenders from the European Central Bank. The total connectedness rises and the net pairwise connections become very strong.

On September 19, the US administration worked on a 700 billion US Dollar plan to rescue banks. The fund was to protect several banks. Some stock prices begin to rise up again. In Germany, the Ba-

${ }^{1}$ EURIBOR is the interest rate at which banks lend to each other in Europe.
Fin (BundesanstaltfürFinanzdiensleistungsaufsicht) prohibited naked short sales to stop the falling prices. The law was valid from the September 20 till December 31. Banking and insurance sector firms were particularly affected: Aareal Bank, Allianz, AMB Generali Holding, Commerzbank, Deutsche Bank, Deutsche Börse, Deutsche Postbank, Hannover Rückversicherung, Hypo Real Estate, MLP and Münchener Rück. Great Britain and the US passed the same law too.

Till September 22, the total connectedness remained high. In these days, several shocks occurred that affected the whole system such that we can hardly connect each single shock to its trigger firm. But for the single days, we can divide the institutions into groups. On September 18, the net-transmitters are Commerzbank, comdirect bank and Allianz and the net-receivers are Aareal Bank, IKB and Münchner Rück. On the September 19, the nettransmitters are Commerzbank, comdirect bank and Allianz and the net-receivers are Deutsche Bank, Postbank, Aareal Bank, IKB and Münchner Rück. On September 22, the net-transmitters are comdirect bank and Allianz and the net-receivers are Münchner Rück and Deutsche Bank. On September 23, the total connectedness began to fall and the strong pairwise connections began to vanish from the system. Mitigating the impacts of the financial crisis and stabilizing the system, the Federal government of Germany lent money to crisis-affected banks and gave guarantees.

Table 4. Timetable of important events in September 2008

\begin{tabular}{|l|l|}
\hline Date & \multicolumn{1}{|c|}{ Event } \\
\hline Sep 9 & Begin of the liquidity crisis. Banks do not trust each other anymore. \\
\hline Sep & $\begin{array}{l}\text { Deutsche Bank holds 29.75\% shares of Postbank and is now the } \\
\text { greatest single shareholder. }\end{array}$ \\
\hline $\begin{array}{l}\text { Sep } \\
15\end{array}$ & $\begin{array}{l}\text { Investment bank Lehman Brothers is bankrupt. } \\
\text { Merill Lynch is acquired by Bank of America. } \\
\text { US administration rescues insurance company AIG. }\end{array}$ \\
\hline $\begin{array}{l}\text { Sep } \\
18\end{array}$ & $\begin{array}{l}\text { Banks can lend up to } 40 \text { billion Euro for one day to overcome their } \\
\text { liquidity difficulties. }\end{array}$ \\
\hline $\begin{array}{l}\text { Sep } \\
19\end{array}$ & $\begin{array}{l}\text { The US administration decides to stabilize the banking system with 700 } \\
\text { billion USD. Hence, a lot of stocks rise, e.g., Commerzbank. } \\
\text { Prohibition of short sales by BaFin. Several stocks of banks and } \\
\text { insurance companies were affected. }\end{array}$ \\
\hline
\end{tabular}




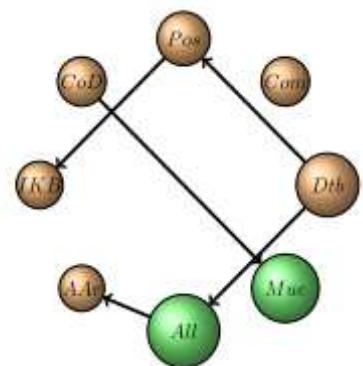

Sep 11, total connectedness 37.84

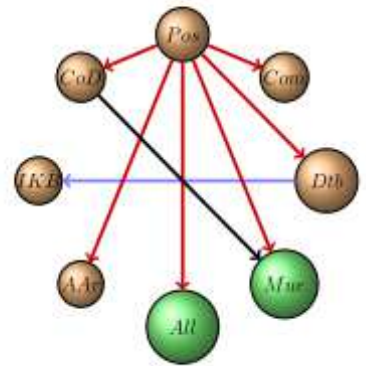

Sep 15 , total connectedness 46.04

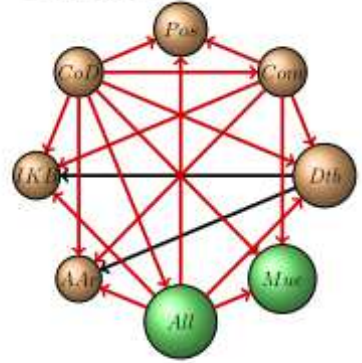

Sep 19, total connectedness 87.52

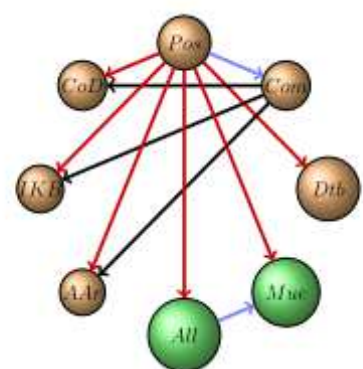

Sep 12, total connectedness 79.91

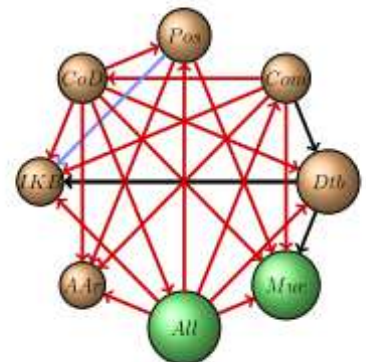

Sep 18, total connectedness 84.92

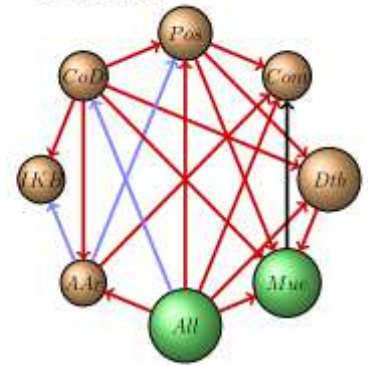

Sep 22, total connectedness 83.63

Fig. 7. We plotted all net pairwise directional connectedness more than 5 . The black edges describe connectedness between 5 and 8, the blue edges between 8 and 10 and the red ones more than 10. The vertices of Allianz and Münchner Rück are marked green as they are insurance companies. The node size is an indicator for the stock market capitalization

2.5. Robustness check. In conclusion of this section, we discuss the robustness of connectedness analysis with respect to the choice of model parameters. These are the VAR order $p$, the rolling window size $\boldsymbol{\omega}$ and the forecast horizon $H$. Furthermore, we consider the Cholesky factorization in comparison to the generalized variance decomposition. The corresponding analyses with different parameters are not reported in this paper, but can be requested from the authors.

2.5.1. Varying the VAR order $p$. We conducted an analysis of dynamic total connectedness during 2008 based on VAR(1) and VAR(5) models in comparison to the VAR(3) model used in section 3 . We observed that total connectedness based on VAR(1) model estimates is about $10 \%$ lower in comparison to the $\operatorname{VAR}(3)$ model, whereas the $\operatorname{VAR}(5)$ model tends to lead to somewhat larger total connectedness. However, in times of crises, e.g., during September and October 2008, the total connectedness measures based on $\operatorname{VAR}(p)$ with $p=1,3,5$ are similar and do not differ that much. Though we see some differences in the total connectedness, its evolution during 2008 is qualitatively comparable for all VAR orders $p=1,3,5$. This leads us to the conclusion that the chosen VAR(3) model is robust with respect to the VAR order.

2.5.2. Varying the rolling window size $\omega$ and time horizon $H$. To check the robustness to the choices of $\omega$ and $H$, we conducted the same total connectedness analysis, as in section 3, for $\omega \in\{75,100,125\}$ and $H \in\{6,12,18\}$. Note that there is no general reason why the connectedness model should be robust to these parameters. Setting $\omega=100$ and varying $H$, we nearly see no differences in total connectedness. If differrences occur, then, they are small. With decreased 
window size $\omega=75$ and varying $H$, we observe differences between the variation of the models and the preferred model with $\omega=100$ and $H=12$ rises with the size of $H$. In non-crisis times, the total connectedness is overestimated, but in crisis times, there are hardly any deviations between the models. Increasing the window size to $\omega=125$ and varying $H$ leads to larger differences between this model and the chosen model for smaller values of $H$. Especially in crisis times, there are almost no differences. In non-crisis times, the total connectedness is underestimated. Qualitatively, the evolution over the year turns out to be very similar for $\omega=75$ and $\omega=125$. We conclude that the results are pretty robust to the choice of rolling window size and forecast horizon.

\subsubsection{Comparison to Cholesky factorization.} Concluding our robustness assessment, we compare our results using the generalized variance decomposition to corresponding results using the Cholesky factorizations. As the latter results crucially depend on the ordering of the variables, it is not suitable for assessing pairwise and total directional connectedness, but it should be robust for total connectedness.

Given the dependence of the Cholesky approach on the ordering, we considered the maximal, the minimal and the average value of total connectedness. The latter are computed considering all possible permutations of the variables ${ }^{1}$. This approach is preferred by Klößner and Wagner (2012) to the method propagated by Diebold und Yilmaz (2014) based on GVDs. Diebold and Yilmaz (2014) used 100 random orderings of the realized stock return volatilities to get the total connectedness by Cholesky factorization and averaged over these 100 orderings. The differences between the GVD approach and the approach of Klößner und Wagner (2012) for the total connectedness are very small for the average, whereas the deviations are huge for the maximum and minimum values. Qualitatively, the evolution of the total connectedness by the GVD and Cholesky factorization are quite similar. Furthermore, for the average Cholesky approach, we varied also the window size $\omega \in\{75,100,125\}$ and the forecast horizon $H \in\{6,12,18\}$. Irrespective of the choice of the rolling window size and the predictive horizon, we observed only small deviations of total connectedness during 2008 between GVD and Cholesky factorization.

${ }^{1}$ We used the R package "fastSOM" by Klößner und Wagner (2012) for getting the values.
Especially in crisis time (September and October), the deviations vanish. Overall, we get that the results are pretty robust to the Cholesky factorization.

\section{Conclusion}

We have conducted a connectedness analysis, as proposed by Diebold und Yilmaz (2014), for eight German financial institutions during the financial crisis in 2008. Using high-frequency intraday stock trading data, we calculate the daily realized return volatility, which serves as the basis of our analysis. We provide several versions of volatility connectedness that help to understand the interplay between financial institutions. In particular, these measures allow to study the evolution of connectedness during crises. In general, connectedness in Germany can be depicted well by using the approach of Diebold and Yilmaz (2014) based on VAR models and GVDs. Our empirical results are nicely interpretable and lead to helpful insight. For example, we see that with the exception of IKB, all firms affected by the financial crisis show large static connectedness. However, a closer look at dynamic connectedness measures reveals that IKB is dominated by one huge peak in "to" connectedness which results in very large static "own" connectedness. Also, as expected, we find pronounced connectedness between firms that, indeed, have contractual obligations, as, e.g., Postbank and Deutsche Bank or Münchner Rück and Allianz. The dynamic analysis shows that connectedness measures can react quickly on shocks occurring at the market. For example, the shocks triggered by IKB, Lehman Brothers or insurance companies immediately lead to an increase of total connectedness. Not expected was the rather low connectedness between Deutsche Bank and the other banks. Nevertheless, this result turns out to plausible indeed, as Deutsche Bank has by far the largest market capitalization among them and it is the only German bank that can be looked upon as a global player. Hence, Deutsche Bank plays in a different league leading to low connectedness to the other German banks. Finally, robustness checks indicate that our empirical results are quite robust to different parameter choices. In summary, the values resulting from this method should not be taken as absolutes, but rather as an indication of connectedness among financial firms. Nevertheless, as it gives insights in the interdependencies between financial institutions it can be helpful tool, e.g., for risk management and asset pricing. 


\section{References}

1. Adrian, T., Brunnermeier, M. (2008). CoVaR. In: National Bureau of Economic Research, Working Paper, No. w17454.

2. Allianz Investor Relations. (2008a). Messages by Allianz Investor Realations.

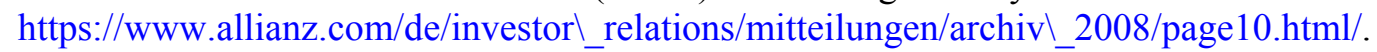

3. Allianz Investor Relations. (2008b). Messages by Allianz Investor Realations. https://www.allianz.com/de/investor__relations/mitteilungen/archiv\_2008/page4.html/.

4. Basel Commitee on Banking Supervision. (2011). Global systemically important banks: Assessment methodology and the additional loss absorbency requirement.

5. boerse.de (Hg.). (2016). VDAX NEW. http://www.boerse.de/boersenlexikon/ VDAX-NEW.

6. Brownless, C., Engle, R.F. (2012). Volatility, Correlation and Tails for Systemic Risk Measurment. Manuscript, Stern School, NYU.

7. Detzer, Daniel, Creel, Jerome, Labondance, Fabien, Levasseur, Sandrine, Shabani, Mimoza, Toporowski, Jan et al. (2014). Financial systems in financial crisis - An analysis of banking systems in the EU, Intereconomics, 49 (2), pp. 56-87.

8. Diebold, F.X., Yilmaz, K. (2012). Better to Give than to Receive: Predictive Measurment of Volatility Spillovers. In: International Journal of Forecasting, 28, pp. 57-66.

9. Diebold, F.X., Yilmaz, K. (2014). On the Network Topology of Variance Decompositions: Measuring the Connectedness of Financial Firms, Journal of Econometrics, 182, pp. 119-134.

10. Diebold, F.X., Yilmaz, K. (2015). Financial and Macroeconomic Connectedness - A Network Approach to Measurement and Monitoring. New York: Oxford University Press.

11. Diebold, Francis X., Yilmaz, Kamil. (2016). Trans-Atlantic Equity Volatility Connectedness. U.S. and European Financial Institutions, 2004-2014, Journal of Financial Econometrics, 14, pp. 81-127.

12. Financial Stability Board (FSB) (Hg.). (2016). Update of group of global systemically important banks (G-SIBs).

13. Hautsch, N., Schaumburg, J., Schienle, M. (2014). Forecasting systemic impact in financial networks, International Journal of Forecasting, 30, pp. 781-794.

14. Hautsch, N., Schaumburg, J., Schienle, M. (2015). Financial Network Systemic Risk Contributions, Review of Finance, 19, pp. 658-738.

15. Klößner, S., Sekkel, R. (2014). International spillovers of policy uncertainty, Economics Letters, 124, pp. 508-512.

16. Klößner, S., Wagner, S. (2012). \{SOM $\}$ : Calculation of Spillover Measures. Version R package version 0.9.

17. Klößner, S., Wagner, S. (2012). Robustness and Computation of Spillover: Measures for Financial Asset Returns and Volatilities.

18. Koop, G., Pesaran, M.H., Potter, S.M. (1996). Impulse Response Analysis in Nonlinear Multivariate Models, Journal of Econometrics, 74, pp. 119-147.

19. Kunisch, S. (2008). Halbjahresrückblich 2008. http://www.ma-review.de/fileadmin/bilder/deal /Halbjahresrueckblick \2008.pdf.

20. Lütkepohl, H. (2007). New Introduction to Multiple Time Series. New York: Springer.

21. Pesaran, H.H., Shin, Y. (1998). Generalized Impulse Response Analysis in Linear Multivariate Models, Economics Letters, 58, pp. 17-29. 